\title{
Acceptance of Orthodontic Therapy according to the Aesthetic Component of the Index of Orthodontic Treatment Need among Schoolchildren - a Cross-Sectional Study
}

\author{
Ruzica Zovko ${ }^{1}$, Kristina Gorseta ${ }^{2}$, Stipo Cvitanovic ${ }^{3}$, Mirela Mabic ${ }^{4}$, Anka Coric ${ }^{1}, Z_{\text {denko Sarac }}^{1}$, Domagoj \\ Glavina $^{2}$ \\ ${ }^{1}$ Medical Clinic in Mostar, Bosnia and Herzegovina, ${ }^{2}$ Department of Pediatric and Preventive Dentistry, School of Dental \\ Medicine, University of Zagreb, Croatia, ${ }^{3}$ Medical Clinic in Rama-Prozor, Bosnia and Herzegovina, ${ }^{4}$ Faculty of Economics, \\ University of Mostar, Bosnia and Herzegovina
}

Correspondence: kgorseta@sfzg.hr; Tel.: + 38598355 553; Fax.: + 38514802159

Received: 20 February 2020; Accepted: 12 August 2020

\begin{abstract}
Objective. Orthodontic anomalies with impaired facial aesthetics and disturbed oral functions have a major effect on emotional and social development. It is necessary to determine the degree of acceptance of treatment. This study includes an evaluation of the Index of Orthodontic Treatment Need (IOTN) according to the Aesthetic Component (AC) of dental health in schoolchildren. Methods. The research included 300 schoolchildren (150 girls, 150 boys) with an age range from 12 to 15 years. An evaluation of the need for orthodontic treatment according to the AC consisted of a ten-grade scale illustrated with a sequence of ten intraoral photographs showing different degrees of acceptability of dental appearance. Results were expressed as absolute and relative frequencies. The Chi-square test (in the absence of the expected frequencies of Fisher's Exact test) was used for testing the significance of differences. Cohen's kappa statistic measure was used for measuring the agreement between the children and dentists. Results. There is a significant substantial agreement between children and dentists in assessing the need for orthodontic treatment. Differences in assessment of the degree of orthodontic anomalies by the doctor of dental medicine with respect to boys and girls, are negligible, and statistical analysis did not show any significant difference. Analysis of the need for orthodontic treatment with respect to the age of the children showed a significant difference. Conclusion. The need for orthodontic treatment is more pronounced in older children, and there is no difference between boys and girls.
\end{abstract}

Key Words: Orthodontic Anomalies • Aesthetic Component (AC) • Index of Orthodontic Treatment Need (IOTN).

\section{Introduction}

Disturbances caused by occlusal anomalies, such as irregular teeth positions in the dental arches and an irregular proportion between the lower jaw and the skull base, are numerous. Dento-facial anomalies are conditions with deviations between the regular morphology, size and function of individual parts or the entire craniofacial complex (1). They are clinically identified as disorders of oral function: phonation, deglutition and mastication, where the greatest personal disturbance caused by these conditions is a facial aesthetics disorder in both children and adults. Abnormal arrangement of teeth in the dental arches during eruption, es- pecially their compaction, results in the inability to eliminate food residues, even with regular oral hygiene. This is related to the development of bacterial flora, as the food gets stuck in retention spaces. Food residues and bacteria products initiate a fermentation process, where acid leads to the demineralization of the firm dental tissues, and has a pathological effect on the periodontal tissues, hence representing a direct aetiological factor for the occurrence of caries and periodontitis $(2,3)$. Aesthetics are one of the main reasons for undergoing orthodontic treatment, and therefore it is considered that the aesthetic component must be represented in diagnostic tools (4). It was clear 
that the patients' perception of their own malocclusion needs to be taken into account.

Orthodontic anomalies, besides functional limitation, also cause psychological effects (5). Orthodontic anomalies, especially in schoolchildren, have gained epidemic proportions. Therefore, countries with well-developed oral health care are conducting active research in order to identify the need for orthodontic treatment, since early treatment significantly reduces the consequences of impaired oral health and facial aesthetics (6). Pronounced orthodontic anomalies in children, accompanied by impaired facial aesthetics and disturbed oral function (speech in particular), have a major effect on emotional and social development in children and adults alike. In children, this occurrence causes introversion, avoidance of contact with the environment, and often such children are ridiculed and taunted by their peers (7). The key to determining prevalence is diagnostics based on carefully aligned criteria, in order to set treatment priorities. Usually this is achieved by means of the Index of Orthodontic Treatment Need, using a Dental Health Component (DHC) and an Aesthetic Component to determine different levels of these needs $(8,9)$. In this undeveloped region of Bosnia and Herzegovina, where oral health care is inadequate, there has been no research on this topic so far. Hence, this research was oriented towards the need for orthodontic treatment using the AC. Since most schoolchildren do not readily accept orthodontic treatment, it is necessary to determine the degree of acceptance of treatment based on their own assessment and assessment by a doctor of dental medicine.

The aim of this study was to analyze the need for orthodontic treatment in schoolchildren of both genders, aged 12 to 15, based on the AC and an assessment by a dental medicine doctor. The research objectives were also to investigate the acceptance of orthodontic treatment by schoolchildren of both genders with a moderate to major IOTN.

\section{Materials and Methods}

The research included 300 schoolchildren of both genders (150 girls and 150 boys) aged 12 to 15 years.
The study was approved by the Ethics Committee of the Rama Community Health Center, in accordance with the Helsinki Declaration. Informed consent was obtained from the parents. The children were informed about the study in an appropriate way and only those children who agreed to participate were included in the study. The sample size calculation was performed by considering the 54.3 percent prevalence of orthodontic treatment need, as measured by the DAI, with a confidence interval of $95 \%$ and $5 \%$ of level of precision. During sampling, the following exclusion criteria were applied: 1) No history of orthodontic treatment, 2) No ongoing orthodontic treatment. This study was conducted in two primary schools in the ProzorRama Municipality from 2015 to 2016. This is a territory where people traditionally live in an environment of similar economic, cultural and educational development, with shared financing institutions and health system organization. At this age, most permanent teeth have erupted (except for the third molar), so the research was not undertaken on individual age groups, but aggregately. Every person had their own health record, showing they had not undergone any form of orthodontic treatment before. All schoolchildren included in the study filled in a questionnaire about their assessments of orthodontic treatment need, and declared their acceptance of treatment.

For examination of the AC of the orthodontic treatment need, we used the model applied by Brock and Shaw (10) for this type of research (Figure 1). The model consists of a ten-grade scale, illustrated by a sequence of ten intraoral photographs showing different degrees of acceptable dental appearance. Considering the orthodontic treatment need, the photographs were grouped into three categories for the purposes of this research: Group 1: 1-4 "no need for treatment"; Group 2: 5-7 "moderate need for treatment"; Group 3: 8-10 "pronounced need for treatment".

According to quantification with the attached ten-grade scale, subjects with occlusal anomalies graded 1-4 do not require any or require minor orthodontic treatment, while the conditions in photographs 5-7 and 8-10 show a moderate or 


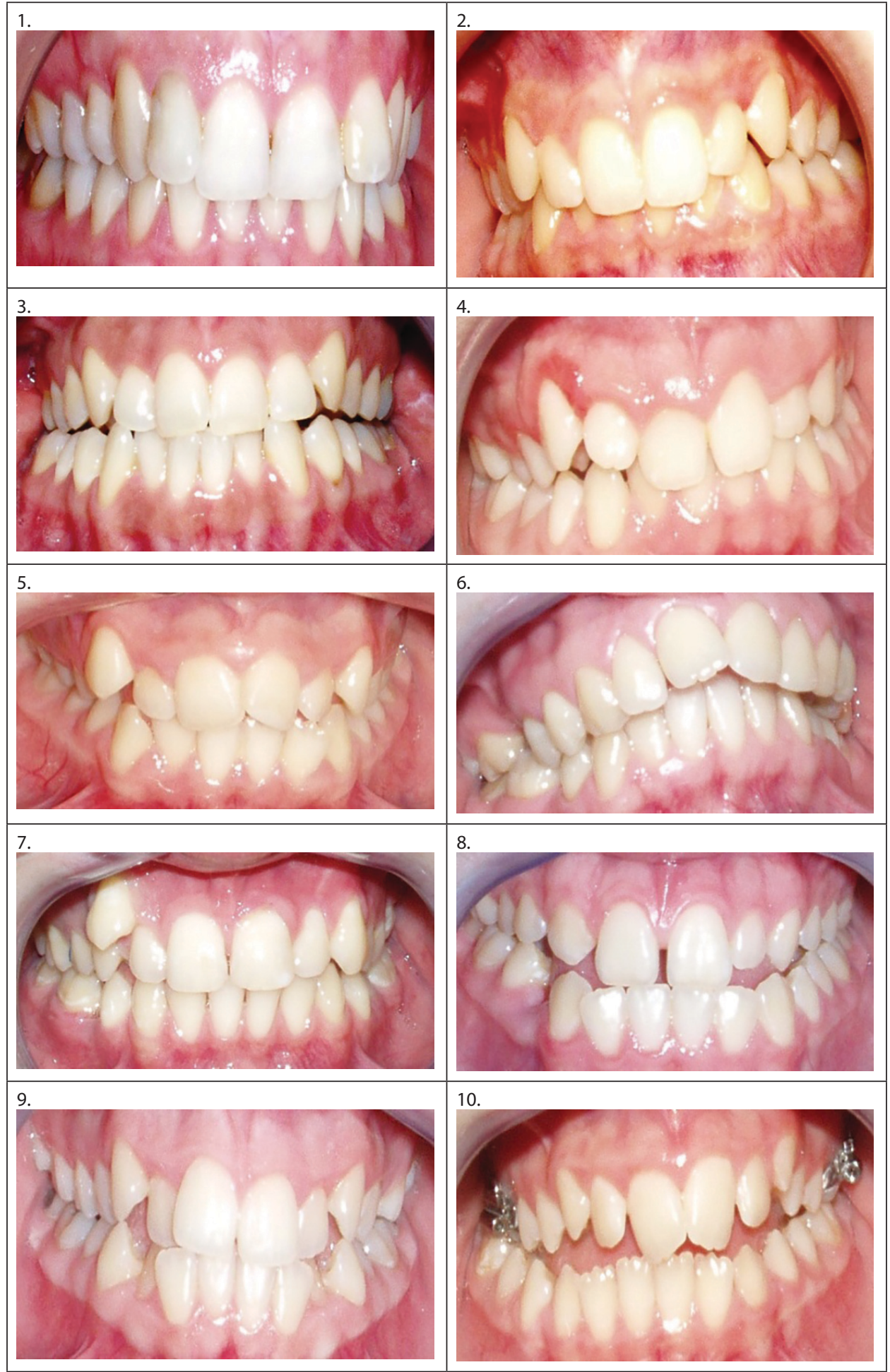

Figure 1. Aesthetic Component of the Index of Orthodontic Treatment Need Scale (photographs 1-10): 1-4 "no Need for Treatment"; 5-7 "moderate Need for Treatment "; 8-10 "Pronounced Need for Treatment". 
major need for treatment so they are considered as priorities. The results were formed by means of assessment by the participants and by a doctor of dental medicine. One researcher, an expert in orthodontics, previously trained in the use of the index, collected the data for each subject. All the participants with an identified moderate or major need for orthodontic treatment (photographs 5-10) were polled and asked whether they would accept the treatment. There were three possible answers: I accept orthodontic treatment. I do not have any particular opinion on the matter, and I do not accept orthodontic treatment.

\section{Statistical Analysis}

IBM SPSS Statistics 25.0 was used for statistical analysis. Results were expressed as absolute and relative frequencies. The Chi-square test (in the absence of the expected frequencies of Fisher's Exact test) was used for testing the significance of differences. Cohen's kappa statistic measure was used for measuring the agreement between children and dentists. The significance limit was set at $\mathrm{P}=0.05$. $\mathrm{P}$ values less than 0.05 indicate statistical significance. $\mathrm{P}$ values that could not be expressed up to three decimal places were expressed as $\mathrm{P}<0.001$.

\section{Results}

There is a significant substantial agreement between children and dentists in assessing the need for orthodontic treatment (Table 1).

Significant substantial agreement in assessing the need for orthodontic treatment was also found in the analysis according to gender: boys and dentists, girls and dentists (Table 2).

Table 1. The Need for Orthodontic Treatment (AC-IOTN): Assessment by Children and Dentists

\begin{tabular}{|c|c|c|c|c|}
\hline \multirow{3}{*}{ Dentist } & \multicolumn{3}{|l|}{ Children } & \multirow{3}{*}{ Total } \\
\hline & No need & Moderate need & Pronounced need & \\
\hline & $\mathrm{N}(\%)$ & $\mathrm{N}(\%)$ & $\mathrm{N}(\%)$ & \\
\hline No need & $260(86.7)$ & $7(2.3)$ & - & $267(89.0)$ \\
\hline Moderate need & $2(0.7)$ & $17(5.7)$ & - & $19(6.3)$ \\
\hline Pronounced need & $3(1.0)$ & $2(0.7)$ & $9(3.0)$ & $14(4.7)$ \\
\hline Total & $265(88.3)$ & $26(8.7)$ & $9(3.0)$ & $300(100)$ \\
\hline \multicolumn{5}{|c|}{ Cohen's Kappa $=0.774 ; \mathrm{P}<0.001$} \\
\hline
\end{tabular}

Table 2. The Need for Orthodontic Treatment (AC-IOTN): Assessment by Children and Dentists according to Gender

\begin{tabular}{|c|c|c|c|c|c|}
\hline & & Children & & & \\
\hline Dentis & & No need & Moderate need & Pronounced need & Total \\
\hline & No need & $129(86.0)$ & $7(4.7)$ & - & $136(90.7)$ \\
\hline & Moderate need & - & $8(5.3)$ & - & $8(5.3)$ \\
\hline Boys & Pronounced need & - & $2(1.3)$ & $4(2.7)$ & $6(4.0)$ \\
\hline & Total & $129(86.0)$ & $17(11.3)$ & $4(2.7)$ & $150(100)$ \\
\hline & Cohen's Kappa $=0.774 ; \mathrm{P}<0.001$ & & & & \\
\hline & No need & $131(87.3)$ & - & - & $131(87.3)$ \\
\hline & Moderate need & $2(1.3)$ & $9(6.0)$ & 0 & $11(7.3)$ \\
\hline Girls & Pronounced need & $3(2.0)$ & - & $5(3.3)$ & $8(5.3)$ \\
\hline & Total & $136(90.7)$ & $9(6.0)$ & $5(3.3)$ & $150(100)$ \\
\hline & Cohen's Kappa $=0.835 ; \mathrm{P}<0.001$ & & & & \\
\hline
\end{tabular}


Significant substantial agreement in assessing the need for orthodontic treatment was also found in the analysis according to age: $12-13$ year old children and dentists, 14-15 year old children and dentists (Table 3).

Comparing boys and girls, the results show a greater need for orthodontic treatment in boys, but the difference is not statistically significant (Table 4).

Analysis of the need for orthodontic treatment with respect to the age of the children showed a significant difference (Table 4). The need for orthodontic treatment is more pronounced in older children.

\section{Acceptance of Orthodontic Treatment by Schoolchildren}

The objectives of this research included determination of quantification and standardization of orthodontic treatment need, and setting priorities for orthodontic treatment based on examples of similar research studies conducted worldwide (8, 9). Assessment by the dentists showed: 14 boys and 19 girls (according to gender) and seven 1213 year old children and twenty-six 14-15 year old children (according to age) had a moderate to major need for orthodontic treatment. No significant difference was found in the acceptance of orthodontic treatment according to gender, nor according to age (Table 5).

Regarding their negative view of the treatment, the subjects pointed out the discomfort of wearing of orthodontic appliances for a long time, and their concerns as to the positive outcome of the treatment.

Table 3. The Need for Orthodontic Treatment (AC-IOTN): Assessment by Children and Dentists according to Age

\begin{tabular}{|c|c|c|c|c|c|}
\hline \multirow[b]{2}{*}{ Dentist } & & \multicolumn{3}{|l|}{ Children } & \multirow[b]{2}{*}{ Total } \\
\hline & & No need & Moderate need & Pronounced need & \\
\hline \multirow{5}{*}{$\begin{array}{l}\text { Age: } \\
12-13\end{array}$} & No need & $145(96.0)$ & 0 & 0 & $145(96.0)$ \\
\hline & Moderate need & - & $5(3.3)$ & - & $5(3.3)$ \\
\hline & Pronounced need & - & - & $1(0.7)$ & $1(0.7)$ \\
\hline & Total & $145(96.0)$ & $5(3.3)$ & $1(0.7)$ & $151(100)$ \\
\hline & Cohen's Kappa $=1.000 ; \mathrm{P}<0.001$ & & & & \\
\hline \multirow{5}{*}{$\begin{array}{l}\text { Age: } \\
14-15\end{array}$} & No need & $115(77.2)$ & $7(4.7)$ & - & $122(81.9)$ \\
\hline & Moderate need & $2(1.3)$ & $12(8.1)$ & - & $14(9.4)$ \\
\hline & Pronounced need & $3(2.0)$ & $2(1.3)$ & $8(5.4)$ & $13(8.7)$ \\
\hline & Total & $120(80.5)$ & $21(14.1)$ & $8(5.4)$ & $149(100)$ \\
\hline & Cohen's Kappa $=0.709 ; \mathrm{P}<0.001$ & & & & \\
\hline
\end{tabular}

Table 4. The Need for Orthodontic Treatment (AC-IOTN) according to Gender and Age: Assessment by Children

\begin{tabular}{|c|c|c|c|c|}
\hline \multirow{3}{*}{ Children } & \multicolumn{3}{|c|}{ Need for orthodontic treatment (AC-IOTN) } & \multirow{3}{*}{ Total } \\
\hline & No need & Moderate need & Pronounced need & \\
\hline & $\mathrm{N}(\%)$ & $\mathrm{N}(\%)$ & $\mathrm{N}(\%)$ & \\
\hline Boys & $129(86.0)$ & $17(11.3)$ & $4(2.7)$ & $150(100)$ \\
\hline Girls & $136(90.7)$ & $9(6.0)$ & $5(3.3)$ & $150(100)$ \\
\hline \multicolumn{5}{|c|}{$\chi^{2}=2.764 ; P=0.297 ;$ Fisher's Exact test } \\
\hline Age: $12-13$ & $145(96.0)$ & $5(3.3)$ & $1(0.7)$ & $151(100)$ \\
\hline Age: $14-15$ & $120(80.5)$ & $21(14.1)$ & $8(5.4)$ & 149 (100) \\
\hline
\end{tabular}


Table 5. Acceptance of Orthodontic Treatment According to Gender and Age

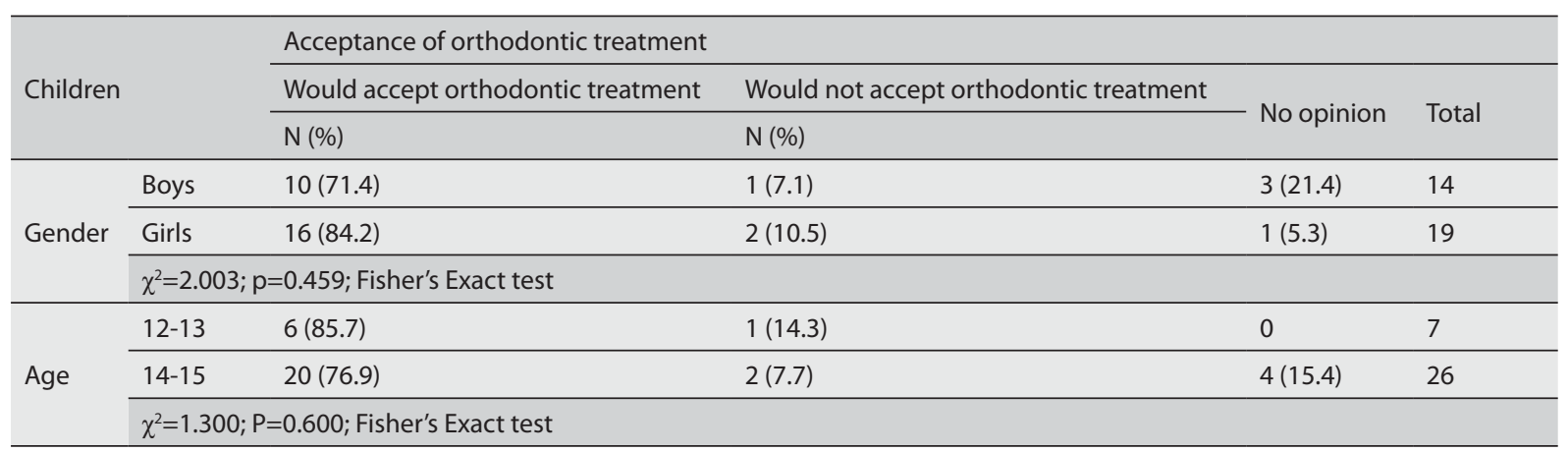

\section{Discussion}

This study of the IOTN performed using the AC in two primary schools in the Prozor-Rama Municipality with respect to children aged 12-15 years, showed a very high degree of malocclusions. We also quantified the degree and priority of treatment due to the high percentage of malocclusions. The research results indicate that, out of the total number of subjects $(300,150$ boys and 150 girls aged 12-15 years), 33 of them (or $11 \%$ ) had a moderate or major need for orthodontic treatment. Similar studies performed in this region verified the existence of malocclusions, but did not determine their degree in order to ascertain treatment priorities (11). Using the IOTN, in different countries, different rates of these needs have been determined. In India, Tak $\mathrm{M}$ et al. showed that malocclusion and orthodontic treatment need was reported among $33.3 \%$ of the study subjects (12). In Europe, in primary school children in Italy, $59.5 \%$ had a need for orthodontic treatment (8), whereas 15$26 \%$ children aged 12-14 in Great Britain had this need (13), and $28.9 \%$ of children aged $8-16$ years in Scotland (14). Linder-Aronson et al. conducted a study in Scotland and showed that the prevailing objective and subjective need for treatment varied in the areas studied (14). The highest prevalence of treatment need was found in areas with a large immigrant population. The prevalence of objective need for treatment varied between $23.8 \%$ and 28.9\%. The subjective need for treatment ranged from $21.6 \%$ to $30.3 \%$. A similar study performed in Germany showed that $26.2 \%$ of the examined children had a need for orthodontic treatment (15). Many studies have shown a major discrepancy between the orthodontic treatment need assessed using the Aesthetic Component (AC), due to the fact that a dento-facial anomaly, such as a lack of teeth in the lateral area, does not always have an effect on aesthetics $(16,17,18)$. Cai et al. showed that a positive relationship $(\mathrm{P}<0.001)$ existed between the young adults' AC and the orthodontist's AC ( $r=0.275)$ (19). Taibah et al. showed a statistically significant but fair agreement between the clinician's AC and students' AC assessments in different age groups (20). It is noteworthy that no significant differences in the need for orthodontic treatment between males and females were observed in the present study. The differences in assessment of the degree of occlusal anomalies by a doctor of dental medicine are negligible with respect to both boys and girls, and they do not show statistical significance. The negative view of treatment is explained by the discomfort of longterm use of orthodontic appliances, and concerns regarding its positive outcome. In regions without an adequate preventive programme there are a large number of malocclusions in children caused by early loss of either primary or permanent teeth.

In addition, the demand for orthodontic treatment has increased due to increasing awareness and perception, resulting in extensive waiting lists. It is essential, therefore, that orthodontists should carefully prioritize and plan the provision of orthodontic treatment. In comparison to other studies, the results obtained in this study are very similar, although our country ranks quite low in socio- 
economic terms. The availability of preventive programs and programs related to oral health care are still not satisfactory. Preventive programmes for early childhood caries are lacking, so this is a direct aetiological factor related to the higher prevalence of orthodontic anomalies (21).

\section{Limitations of the Study}

It is important to point out some limitations of this study. The IOTN is basically an epidemiological index that has limitations in assessing the treatment needs of individual patients. The studied indices are epidemiological tools that aim to assess the degree of need for treatment, not to make diagnoses or assist in orthodontic planning.

\section{Conclusions}

The IOTN may be adequate for public health planning and epidemiological purposes. On the basis of the results of this research, it may be concluded that there is still high prevalence of occlusal anomalies in the examined region, especially those with a moderate or major need for orthodontic treatment. The need for orthodontic treatment is more pronounced in older children, and there is no difference between boys and girls.

\section{What Is Already Known on this Topic:}

Professional specialist assessment of malocclusion involves assessing both objective and subjective factors, but the patient's self-perception and aesthetic perceptions cannot be underestimated. Many occlusal indexes have been established to perform such estimations and categorize treatment need severity, such as the occlusal index, treatment priority index, and dental aesthetic index.

\section{What this Study Adds:}

A better understanding of patients' perception of their malocclusion severity is an essential step in orthodontic treatment planning. It is necessary to measure their aesthetic self-perception and the degree of acceptance of the treatment. This would give the orthodontist information about the patient's expectations and improve cooperation with patients.

Authors' Contributions: Conception and design: RZ, SC and DG; Acquisition, analysis and interpretation of data: KG, MM, and AC; Drafting the article RZ, SC and ZS; Revising it critically for important intellectual content: KG, MM and DG; Approved final version of the manuscript: RZ, KG, SC, MM, $\mathrm{AC}, \mathrm{ZS}$ and DG.
Conflict of Interest: The authors declare that they have no conflict of interest.

\section{References}

1. Ciuffolo F, Manzoli L, Attilo M. Prevalence and distribution by gender of occlusal characteristics in a sample of Italia secondary school students: a cross sectional study. Eur J Orthod. 2005;27(6):601-6.

2. Warren J, Bishara E. Duration of nutritive and nonnutritive sucking behaviours and their effects on the dental arches in the primary dentition. Am J Orthod. 2002;121(4):347-56.

3. Chew T, Aw L. Appropriateness of orthodontic referrals: self-perceived and normative treatment needs of patients referred for orthodontic consultation. Community Dent Oral Epidemiol. 2002;30(6):449-50.

4. Alkhatib MN, Bedi R, Foster C, Jopanputra P, Allan S. Ethnic variations in orthodontic treatment need in London schoolchildren. BMC Oral Health.2005;5:8.

5. Reshitaj A, Reshitaj K, Bytyqi B. Assessment of Orthodontic Treatment Need in Kosovar Children. The Open Public Health Journal. 2019;12:321-4.

6. Triassi M, Viola P, Angelillo F. The prevalence of malocclusions in schoolchildren in Naples. [in Italian] Med Prev. 2003;26:200-8.

7. Trulsson U, Strandmark M, Mohlin B. A qualitative study of teenagers' decisions to undergo orthodontic treatment with fixed appliance. J Orthod. 2002;29(3):197-204.

8. Nobile C, Pavia M, Fortunato L, Angelillo F. Prevalence and factors related to malocclusion and orthodontic treatment need in children in Italy. Eur J Public Health. 2007;17(6):631-41.

9. Tickle M, Kay J, Bearn D. Socio economic status and orthodontic treatment need. Community Dent Oral Epidemiol. 1999;27(6):413-8.

10. Brock H, Shaw W. The development of an index of orthodontic treatment priority. Eur J Orthod. 1989;11(3):30920.

11. Topić B. Primary dental care for children in Bosnia and Herzegovina. [in Croatian] In: Rajić Z, editor. Primary dental care. [in Croatian] Zagreb: JUMENA;1989. p. 10915 .

12. Tak M, Nagarajappa R, Sharda AJ, Asawa K, Tak A, Jalihal S, et al. Prevalence of malocclusion and orthodontic treatment needs among 12-15 years old school children of Udaipur, India. Eur J Dent. 2013;7(Suppl 1):S045-53.

13. Tickle M. Improving the oral health of young children through an evidence-based approach. Community Dent Oral Epidemiol. 2006;23(1):2-4.

14. Linder S, Bjeeehorn K, Forsberg M. Objective and subjective need for orthodontic treatment in Stockholm County. Swed Dental J. 2002;26(1):31-40. 
15. Tausche L, Luck O, Harzer W. Prevalence of malocclusions in the early mixed dentition and orthodontic treatment need. Eur J Orthod. 2004;26(3):237-44.

16. Adullah B, Rock P. Assessment of orthodontic treatment need in 5. 112 Malaysian children using the IOTN and DAI indices. Community Dent Health. 2001;18(4):242-8.

17. Gosney MB. An investigation into some of the factors influencing the desire for orthodontic treatment. Br J Orthod. 1986;13(2):87-94.

18. Souames M, Bassigny F, Zenati N, Riordan PJ, Boy-Lefevre ML. Orthodontic treatment need in French schoolchildren: an epidemiological study using the Index of Orthodontic Treatment Need. Eur J Orthod. 2006;28(6):605-9.
19. Cai Y, Du W, Lin F, Ye S, Ye Y. Agreement of young adults and orthodontists on dental aesthetics \& influencing factors of self-perceived aesthetics. BMC Oral Health. 2018;18(1):113.

20. Taibah SM, Al-Hummayani FM. Agreement and association between normative and subjective orthodontic treatment need using the Index of Orthodontic Treatment Need. J Orthod Sci. 2019;8:1.

21. Zovko R, Cvitanović S, Mabić M, Ćorić A, Vukojević K, Goršeta K, et al. The prevalence of orthodontic treatment needs of school children in northern Herzegovina. Acta Med Acad. 2017;46(1):27-33. 